actually been put into practice. In Venezuela, British Guiana, Chile, the United States, Sardinia, Italy, Greece and Cyprus, malaria has either practically or entirely ended, as it has also in a rural area of Bombay Province holding some two million people, and in the extensive Kharga and Dhakla oases of Egypt. There have been marked reductions in other places, including the Union of South Africa, and invading foreign mosquitoes have been evicted from Brazil ${ }^{21}$ and Egypt.

Two entirely separate principles have been concerned in this. The first is the total eradication of anopheline species (or anopheline genus in Cyprus), made possible by organisational techniques not dependent on new insecticides and ensuring perfection of local work; this has so far been used in areas with some natural protection against re-invasion in Brazil, Egypt, Cyprus and Sardinia. The other is the country-wide application of D.D.T. residual indoor sprays to all houses and anopheline shelters, producing control of anophelines at a level below that necessary for malaria transmission but not of the perfection needed for eradication; it is this process which is largely responsible for the recession of malaria in the United States, Venezuela, British Guiana, Chile, Italy, Greece, the Union of South Africa, and parts of Bombay Province.

The exponents of the two methods are in friendly rivalry; their methods too young as yet for accurate comparison, but both are practicable on a large scale. The tropical and subtropical world stands divided into two sections, one of which has, and one of which has not, attempted to apply either of these principles. It is regrettable to find tropical Africa in the latter group, though as yet unresolved doubt has been thrown on the value of D.D.T. in that country ${ }^{22}$. The Malaria Committee of the World Health Organisation has, however, agreed to support a large eradication scheme in the heart of that continent, and if D.D.T. should be valueless there 'Gammexane' (the gamma isomer of benzene hexachloride) could almost certainly take its place.

The story of these stages and of present trends was told in the Ross Institute Exhibition. If it succeeds in stimulating the British application of these new methods, the Jubilee will have been of real value.

${ }^{1}$ Laveran, A., Bull. Acad. Med., Paris (Nov. 23, 1880).

"Marchiafava, E., and Bignami, A., "On Summer--Autumn Malarial Fevers" (London: The New Sydenham Society, 1894).

${ }^{8}$ Manson, P., Trans. Linn. Soc. (Zoology), 14, 304 (1878).

- Manson, P., Brit. Med. J. (Dec. 8, 1894).

' Ross, R., Brit. Med. J. (Dec. 18, 1897).

'Manson, P., Lancet (Aug. 20, 1898).

'Manson, P., J. Trop. Med. (Aug. 1898).

'Manson, P., Brit. Med. J. (Sept. 24, 1898).

'Ross, R., Brit. Med. J. (Feb. 18, 1899).

"Bastianelli, G., Bignami, A., and Grassi, B., Atti. d. Reale Acad. d. Lincei (Jan. 8, 1899).

${ }^{11}$ Ross, R., Brit. Med. J. (Sept. 9, 16 and 30 and Oct. 14, 1899).

${ }^{12}$ Correspondent, Brit. Med. J. (Dec. 8, 1900).

${ }^{18}$ Lister, Lord, Brit. Med. J. (Dec. 8, 1900).

"Watson, M., J. Trop. Med. (Nov. 16 and Dec. 1, 1903 and April 1, 1905).

${ }^{16}$ Ross, R., Liverpool School of Tropical Medicine, Memoir 9 (University Press of Liverpool, 1903)

${ }^{16}$ Ross, G. Park, Quart. Bull. Health Org., League of Nations, 5, 114.

${ }^{17}$ De Meillon, B., Quart. Bull. Health Org., League of Nations, 5, 134.

${ }^{18}$ Kikuth, W., Deut. med. Wochschr., 58, 530.

"Shortt, H. E., and Garnham, P. C. C., Trans. Roy. Soc. Trop. Med. and Hyg., 41, 785. 20 WHO(IC) Expert Committee on Malaria. Report of Second Session.
WHO.IC/Mal./25 (June 8, 1948).

"Soper, Fred L., and, Wilson, D. Bruce, "Anopheles Gambice in Brazil, 1930-1940" (The Rockefeller Foundation, New York,
1943).

"suirhead Thomson, R. C., Bull. Ent. Res., 38, 449.

\section{THE POST OFFICE RESEARCH STATION}

$\mathrm{T}$ HE earliest experimental work in connexion with the telephone and telegraph services of the General Post Office is recorded to have taken place in 1878. It was, however, not until 1904 that one or two members of the Engineering Department were relieved of their administrative duties to enable them to pursue investigations of a purely experimental nature in a room set aside for the purpose in the Central Telegraph Office. In 1909, the 'Research Section' was recognized as a separate entity, and additional laboratories in a nearby building were allotted to it. Natural expansion of the section, curbed during the First World War, was accelerated when hostilities ceased, and a site of eight acres was acquired for a research station at Dollis Hill in northwest London and about seven miles distant from the Central Telegraph Office. The work was transferred to this site in 1921, when the accommodation took the form of ex-army huts; the present permanent buildings were formally opened in 1933. The activities of the Research Station expanded steadily during the inter-war period, and during the Second World War they were diverted to deal almost entirely with objectives having immediate military applica. tion. Arrears of normal development of research for the Post Office's services now require an accelerated expansion, which is being effected as rapidly as present circumstances permit.

There are at present about twenty buildings at the Research Station, used as laboratories, workshops and offices by the Research and the Radio Development Branches of the Engineering Department of the Post Office. The present staff totals about 860 , of whom about 470 are directly engaged on experimental or theoretical work (including some 275 who are engineers or scientific workers with full professional qualifications or have nearly attained them). About two hundred are employed in the workshops and drawing office. The experimental work of the Department is not confined to the Research Station; there are small laboratories in other parts of the country, and some experimental work has to be done in the field.

The activities of this Research Station are mainly directed towards improved and economical working of Post Office services, especially the telecommunication services, because for these there is wide scope and need for the application of the development of physical science. Apart from some radio equipment, almost all the necessary plant for these services is obtained by purchase from manufacturing companies. For the development and introduction of new types of apparatus into service, the Post Office maintains close liaison with the principal British manufacturers of telecommunication equipment, and a regular pro. cedure exists for exchanging information concerning, and co-ordinating the development of, much of the equipment that is procured. There is also liaison and, when necessary, co-ordination with other Government research establishments and, on the international plane, with other telecommunication administrations. Broadly speaking, therefore, the main function of the Research Station at Dollis Hill is to contribute to advances in telegraphy, telephony and radio and to give guidance on their applications to Post Office services. Some of the investigations, important though limited in scope, 
arise from the day-to-day operation of the services and are concerned with existing plant; others are of a long-term character and represent, perhaps, seeds of the telecommunication plant of the future.

Many of the developments (to which the Research Station has contributed) produce results which are by no means immediately obvious to the users of the telecommunication services. The continued, and sometimes rapid, growth of the telephone network in Great Britain could not have been achieved, or only at much greater expense, without entirely new techniques in telephone transmission, such as the use of one pair of conductors to provide speech channels for many simultaneous conversations. Economies resulting from the introduction of more efficient types of equipment cannot be made to give immediate benefit to the users, in terms of lower charges, because, for the very large and dispersed plant which comprises the telephone network, any largescale replacements must necessarily be spread over a very long period. When costs of labour and materials are tending to rise, the effect of such economies is more likely to appear as a lower increase in the charges for the service than would otherwise be necessary. On the other hand, some developments, for example, those which open up new services or facilities for the user, are more obvious; a case in point is the 'speaking clock'. This was the result more than eleven years ago of research into an electric drive starting from a 'free' pendulum and other research on sound-recording on glass disks.

Modern technique for telephone transmission over long land-line routes is to concentrate a number of telephone conversations on to a single pair of conductors, the conversations being separated on the route by occupying different bands of the frequency spectrum. Thus, the traffic capacity of a route is determined by the total band-width of frequencies it can carry rather than by the number of conductors it contains. With wide-band amplifiers (or 'repeaters') spaced at intervals of about six miles on a modern coaxial (or concentric) type of cable, two coaxial tubes can carry more than six hundred separate conversations simultaneously. This technique of wideband transmission is being still further developed for the transmission of television to programme centres at different parts of Britain. Short lengths of wires in ordinary telephone cabling can be 'equalized' for carrying television signals locally, but for long. distance line transmission of television, the newer types of cable are essential.

By means of frequency separation, several telegraph transmissions can be sent simultaneously over a single telephone circuit independently of whether the telephone circuit is on a radio link, a coaxial cable, or by normal transmission over a pair of wires.

The Post Office Research Station has played a leading part in the development of semi-automatic means of switching long-distance telephone circuits. These enable the trunk operator at the calling end to actuate switches by dialling over the long-distance line and avoid the delay which arises when she is dependent on the assistance of other operators at the remote exchanges. The methods of dialling which are used in local areas could not be extended to the long-rlistance lines, and a system had to be worked out in which all the signals could be transmitted by currents in the speech frequency range without mutual interference between speech and signals. This system is now working on more than three thousand British long-distance circuits.
For telephoning overseas, either submarine cable (for the shorter distances) or radio links have to be used. In the case of the cable, a substantial advance has been made towards increasing the band-width of frequencies (and hence the number of simultaneous conversations) transmitted by inserting a submerged repeater. The repeater has to be capable of continuous operation under water without any maintenance for several years, with power for its valves supplied along the cable. The repeater which the Research Station constructed in 1943 for the Holyhead - Isle of Man cable was the first submerged repeater to be inserted in a working telephone cable anywhere in the world. The scheme is being developed to enable several repeaters to operate along a submarine cable, with facilities for testing and supplying power to each one from the shore ends.

Long-distance, short-wave radio links have been greatly improved since their inception by the use of single-sideband radio transmitters and receivers. On the trans.Atlantic link, reception from the United States has been made much better by the employment of special receivers and an aerial system, two miles long, installed at the radio station at Cooling (Kent). This equipment separates the mutually interfering waves by which the signals arrive after successive reflexions from ionized layers in the upper atmosphere, and so reduces the effects of distortion and noise. The study of other means for dealing with these effects has been facilitated by a laboratory device for simulating them under controllable conditions. Since 1934, radio links on much shorter wave-lengths have been used for extending the telephone network to islands around the coast of Britain ; equipment operating on the frequency-modulation system was first installed on one of these links in 1942.

The Post Office not only operates radio telephone and telegraph services to all parts of the world, including ships at sea; it is also the Department responsible for control and regulation of radio communication. This responsibility involves the need for very exact measurements of any frequency which may be used. The applications of piezo-electric quartz crystal vibrators has been studied since 1925 for frequency control of radio transmitters and for frequency measurement, and the Research Station possesses one of the most comprehensive frequency standard installations in the world. It has provided quartz clocks, the most accurate timekeepers now known, to the Royal Observatory, Greenwich. Other piezo-electric materials are being studied for various applications, notably as components in the electrical circuits used for frequency selection and separation.

Telephone instruments are electro-acoustic devices, so there is need for acoustical as well as electrical measurements; the techniques for acoustical measurement have been developed much more recently than their electrical counterparts. The Research Station has contributed to these developments and it maintains a standard and equipment for the measurement of sound pressures at any desired point, in the open or in a confined space, so that objective measurements of the performance of telephone instruments of any type can be made in conditions appropriate to their use. It also has to set and maintain a standard of 'telephone transmission', which is based on subjective tests and is therefore of a less tangible nature, combining physics with physiology. Record. ing of sound is studied for special applications by the Post Office; two techniques have received particular attention, namely, sound tracks on glass 
disks for frequent repetitions of short announcements, and lacquer-coated metal disks for high-quality gramophone recording, usable (for short life) by direct play-back.

New developments and applications of electronic devices are of vital importance to telecommunications. Facilities for the manufacture of experimental types of thermionic valves enable, for example, knowledge to be built up concerning the causes of their eventual failure and may be helpful towards the provision of the very long-life valves required for submerged repeaters. Such facilities also open the way for development of a few special valves for special uses. Techniques of application, such as are used in electronic computers, are studied ; in fact, an elementary form of electronic computer has been made for dealing with some specific problems of plant provision and arrangement at automatic exchanges.

The main exception to the concentration of effort at the Research Station on telecommunication problems is the work that is being done to explore the practicability of introducing more mechanical processes in the handling of mail. Machines incorporating photo-electric devices can be devised to work at high speed for stacking letters, all with the stamps in correct position to be fed into stamp-cancelling machines, and also for enabling sorters to direct letters into a much larger number of sorting compartments than can be reached by hand. Considerable experimental and development work is necessary before any machines of this kind can be proved to be practicable.

\section{LAND AND POVERTY IN THE MIDDLE EAST}

$\mathrm{D}$

URING the Second World War, the Middle East Supply Centre-the history and achievements of which should be made public before memory fades-acted in various directions as a regional authority over an area embracing about fourteen territories, and extending from Persia to Tripolitania, and from Cyprus to Ethiopia. One of its important short-term objectives was to encourage increased food-production in the Middle East territories, to offset the unavoidable restrictions due to war conditions. This immediate objective threw into sharp relief the need for a comprehensive regional survey of the basic underlying problems of the Middle Eastin particular, land utilization, peasant economy and social organisation-and this task, among others, was given to an Anglo-American Scientific Advisory Mission, the reports of which have now been published by the Stationery Office*. War conditions threw the Middle East territories into close association, and emphasized the fact that they had many common basic obstacles to overcome before any post-war social and economic development was possible.

There were high hopes that some form of regional organisation would succeed the Middle East Supply Centre, to serve these non-political aims. But political inexperience and short-sighted nationalism were too strong. Chatham House has, not for the first time, attempted to fill the gap by publishing a series of studies on social and economic problems in

* The Agricultural Development of the Middle East. By Dr. B. A. Keen. 58. net.

Middle East Sclence. By Dr. E. B. Worthington. 78. 6d. net.

Rural Education and Welfare in the Middle East. By H. B. Allen. Animal Industry in the Middle East. By Dr. N. C. Wright (in

preparation).
(London: H.M. Stationery Office, 1946.) the Middle East. The pamphlet* under review is the first of the series; it deals with Egypt and the Fertile Crescent-Palestine, Transjordan, Syria, Lebanon and Iraq. Dr. Warriner describes the vicious circle enclosing the peasant cultivator in these regions; but the description is equally true for other Middle East countries, and for India. It is essentially an absentee landlord system, with a form of land tenure under which the tenant suffers the maximum disadvantages. Government of the country is largely in the hands of the landlords, most of whom believe their immediate interests would be threatened by any measures designed to improve the tenants' lot. The tenant is wrapped in a fatalism, which is founded on his poverty and helplessness, and reinforced by the technical difficulties of agriculture-especially of peasant farming -in tropical and sub-tropical climates and soils. The social and environmental circumstances that brought about in England the change from the open three-field system to the four-course rotation on enclosed farms do not exist in the Middle East.

Dr. Warriner examines in detail the alternative possibilities. Although most of the suitable land and a good deal of the marginal areas are already settled to capacity or beyond, there are under-populated spaces in the Jezira region of Syria; in Iraq, with better regulation of water supplies, there could be absorbed some five million people, and she points out, as one item in the immensities of the Middle East problem, that this is an authoritative figure for the surplus rural population in Egypt alone.

On the question of quick technical improvements in agricultural methods, Dr. Warriner rightly concludes that these are strictly limited, first, by our present lack of knowledge of tropical agricultural science (a point that cannot be overstressed), and secondly, by the limitations of the existing system of peasant agriculture. Further, such improvements could only be short-range palliatives, for, in the present stage of social emergence of the peasant, any increase in output per acre is more than offset by an increase in the population. At present there appear to be two possibilities only for increasing the output : the development of irrigation under State ownership and control; and, in the drier areas, mechanized dry farming on a village co-operative basis. Both involve a basic change in land tenure customs, and the second especially calls for less, not more, workers per acre.

Dr. Warriner discusses my first proposal for a tripartite organisation that would circumvent the grave obstacles of land ownership and inheritance laws. The proposal is as follows. The Government takes over, on a long lease, land from its present owners, and sub-leases the whole area to a body of the public utility corporation type. This body reconditions the land, divides it into economic units and lets them to tenant farmers for whom it performs certain desirable services--such as bulkmarketing of any cash crops-and from whom it requires certain standards of farming as a condition of the lease. In concluding that this model would not be generally applicable, because it depends on the existence of a special market for which the corporation can finance sales and organise production in relation to the market, Dr. Warriner has rather missed the point of the proposal. It is true that in

* Land and Poverty in the Middle East. By Doreen Warriner. (Middle East Economic and Social Studies.) Pp. vii + 149. (London and New net. 